\title{
Virtual Worlds: An Overview and Pedagogical Examination
}

\author{
Dr. Randall Sadler \\ University of Illinois at Urbana-Champaign, Urbana-Champaign, USA
}

(Article received 15 December 2011; final version received 16 January 2012)

\begin{abstract}
Virtual Worlds (VWs) like Second Life provide a multiuser 3-D environment that may be utilized for either classroom-based or autonomous language learning. While Second Life is one of the most popular VWs at the current time (especially if differentiated from Massively-Multiplayer Online Games like World of Warcraft), there are a number of other VW platforms that, taken together, dwarf Second Life in terms of users. A few of these include: Active Worlds, Entropia Universe, Furcadia, Club Penguin; and MMOGs like the aforementioned World of Warcraft, Runescape, Lineage II, etc. In addition to these worlds, there are also more customized environments such as Croquet and OpenSimulator. As researchers and teachers of languages, our challenge is to determine which of these environments, if any, is appropriate for the group(s) of students we wish to teach and/or study. This article will provide a rationale for the use of VWs in education and also an overview of some of the most applicable Virtual Worlds and discuss the strengths, weakness, and dangers of each.
\end{abstract}

\section{Introduction}

Neo: I thought it wasn't real.

Morpheus: Your mind makes it real.

(The Matrix, 1999)

Virtual Worlds (VWs) have existed (at least in fiction) for many decades. Some readers of this article may have first been exposed to the basic concept on television in shows like Star Trek: The Next Generation (1987), where the starship Enterprise was equipped with a number of holodecks that the crew could use for both entertainment and work. By stepping into the holodeck they seemed to enter a new environment that moments before had been a large empty room. The holodeck might have taken the form of a 1920's office for a detective, a beach, or a simulated engine room that could be used for safe experimentation. The scenes created in the holodeck could include buildings, furniture, plants, or even people; all of which could be interacted with in a way that felt like reality. More recently, as indicated by the quote at the start of this article, many of us learned about Virtual Worlds through The Matrix, where almost all 
humans "lived" in a VW without ever realizing it. This idea has also been explored in books, with many crediting stories like Victor Vinge's True Names (1981), William Gibson's Neuromancer (1984), and Neal Stephenson's Snow Crash (1992) as early predictors of this technology.

Unfortunately for fans of the Star Trek holodecks, the VWs that actually do exist today do not allow us to enter a virtual reality in quite the way that is represented in fiction. However, as I will discuss in this article, today's VWs can be used by both teachers and their students to enhance the learning process in a number of way. In particular, this essay will discuss the potential of VWs to enhance language learning, beginning with a deeper discussion of what they are, followed by a broad overview of some of the VWs available. Next, several VWs with potential for language learning will be examined in more detail, including some of the pros and cons of each and how they might be used in the language learning process.

\section{What are Virtual Worlds and why should we use them?}

Rather than existing in a holodeck (or requiring a direct plug into the brain as in The Matrix, the VWs of today exist on our computers and we interact with the environment on the screen via our keyboards. As discussed in Sadler (2011), all VWs share some common features, including:

- On-line 3D environment. This may simulate the real world, a historical reconstruction (e.g. ancient Edo, Japan as shown in Figure 1), or something that exists only in fiction (e.g. A space city).

- Avatars. Avatars are the in-world representations of real people who control them (see some samples of avatars in SL in Figure 1).

- Real-time Interactivity. VWs include the possibility of interacting with other avatars in the environment in real time (synchronous communication), and usually with a range of objects in that VW.

- 24-hour Accessibility. As opposed to interacting with a friend via a program like Skype ${ }^{\mathrm{TM}}$, where the potential for interaction only exists as long as the program is open and both parties are connected, a VW should be open and accessible 24-hours a day.

- Persistence. When a user logs out of a VW, their avatar, and the actions taken by that avatar, are not deleted.

- Social Space. Although VWs may vary in look and theme, all VWs are primarily social spaces that exist for the purpose of humans interacting via their avatars.

- Numbers. In most VWs there are many players (sometimes in the hundreds of thousands) online in the world at the same time. Given the social nature of these spaces, underpopulated VWs tend to fade away quickly as users lose interest. 
Some readers may be familiar with one very popular cousin of VWs-Massively Multiplayer Online Role-Play Games (MMORPGs). While the difference between a VW and a MMORPG may often be blurred, MMORPGs like World of Warcraft share the features of VWs but their primary concern is the role play component, often in the form of combat gaming. While some Virtual Worlds like Second Life (see Figure 1) may have areas where this type of gaming can take place, the social component of VWs is their main reason for existing. In addition, VWs are often used for education, business meetings, and commerce. Some VWs (e.g. Second Life) even have their own virtual currencies and economies, with some players earning their real life incomes by selling virtual products in that world. While this may seem like a very strange concept to some, it is worth noting that many of the players in these worlds have never bought a $\mathrm{CD}$ in real life (let alone an old fashioned record), but only "own" electronic versions of the albums or songs they obtained from online businesses like iTunes. The students many of us deal with today communicate with their friends virtually (via text messages and email), do their buying — and even selling — virtually (via iTunes, Amazon.com, and eBay), and do much of their socializing virtually (via Skype, VWs, and MMORPGs). In other words, for the students of today, the virtual is real. 


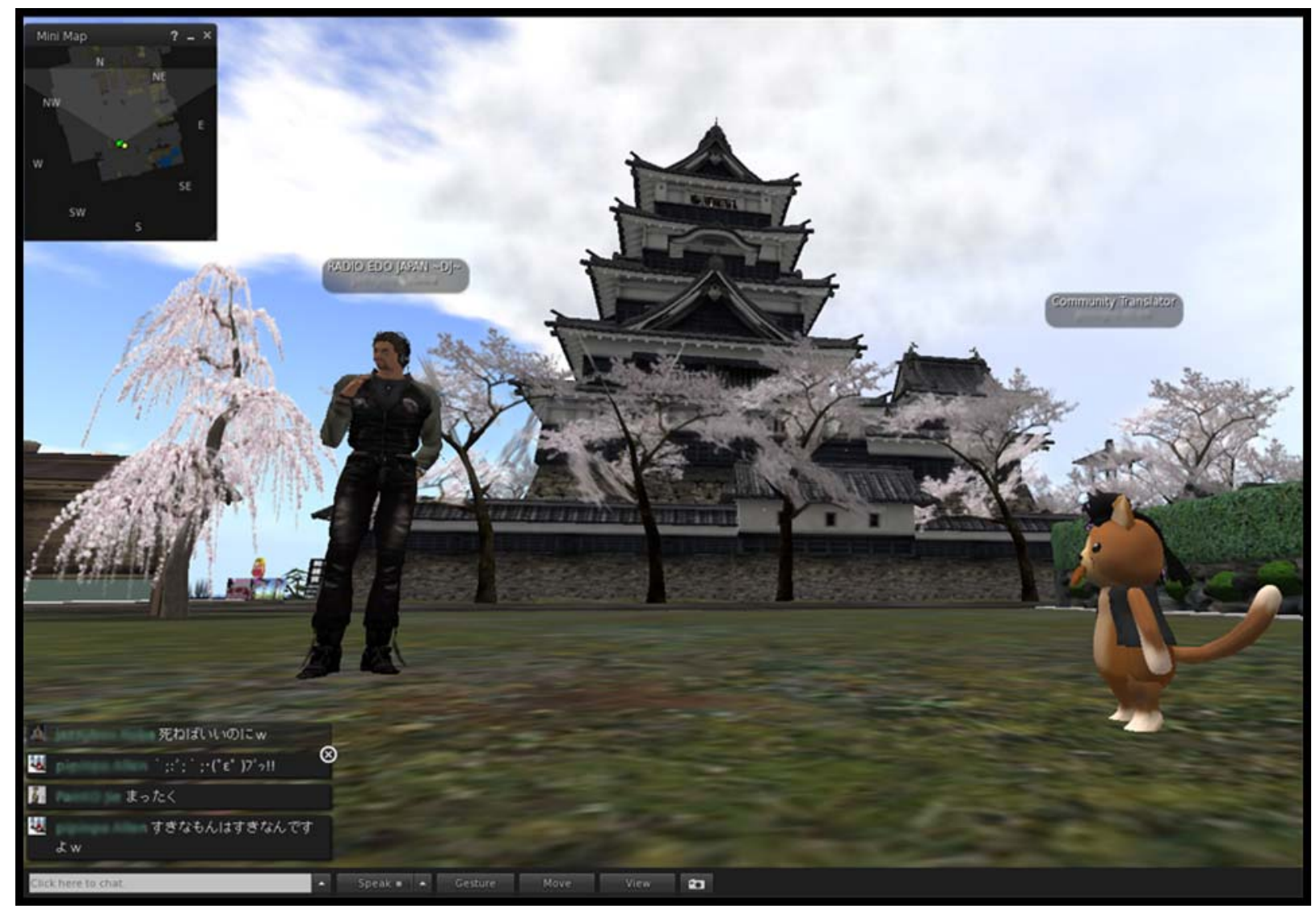

Figure 1. Second Life Ancient Edo Japan ${ }^{1}$

When choosing which technologies to use to enhance our students' language learning, one factor to consider is how widespread the technology is. While all of our students should be familiar with email, are they familiar with VWs? Some estimates regarding the number of users of VWs put the world-wide number at well over 800 million users in 2009, with the 2011 estimate now surpassing one billion users (KZERO, 2011). Data from this same organization (see Figure 2) also indicates that the number of users of these virtual environments has continued to rise amongst all age groups. As seen in the figure, the largest number of users comes from the 10-15 age range, with over 560 million current users. However, even more startling than this number is the realization that this is over twice the number of users from just two years before. This heavy increase carries across all age groups, with the most rapid growth in the 15-25 age group, where the number of users quadrupled in that time period. These numbers make it clear that if we wish to use the technology that our students are engaged in, VWs should certainly have role to play in language education. 


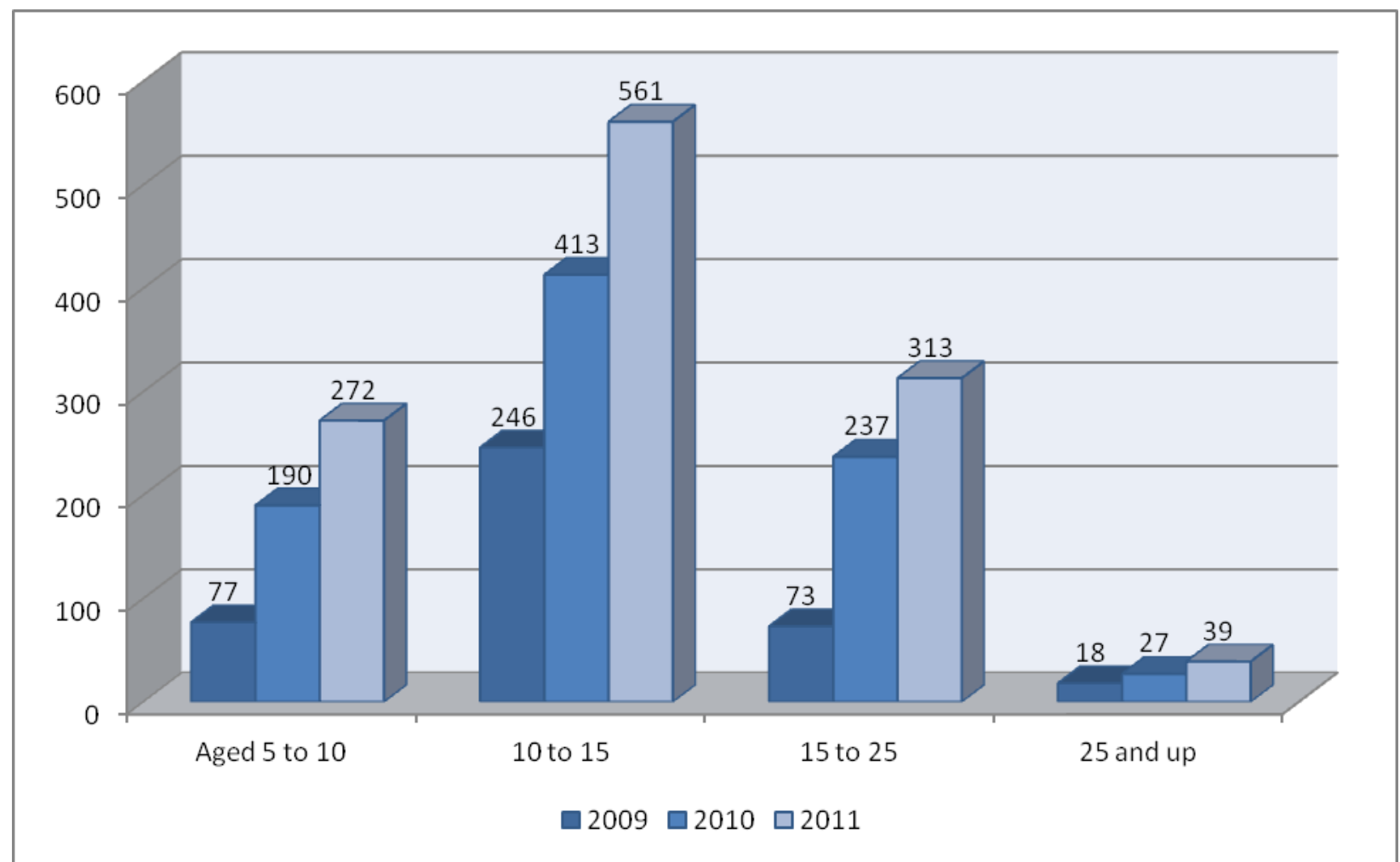

Figure 2. Increase in VW accounts 2009-2011 (millions of users); Source: KZERO, 2011

A primary reason that these environments are so popular is because there are so many to choose from. One website that focuses on these types of games currently lists 337 MMORPGs (Mmohut, 2012) while a second—which includes both MMORPGs and VWs-includes 577 (mmorpg.com, 2012). However, since both of these sites are English-based, it is certain that there are hundreds of games not listed that are played solely in languages other than English.

The number of active users in different VWs can vary widely, but many of the popular ones have millions of users, with many thousands of users in-world at any time. As the amount of VWs has increased, there has also been a trend towards environments aimed at specific age levels and interests. This trend is illustrated in Figure 3, which shows the three most popular VWs for seven different age groups (KZERO, 2011). 


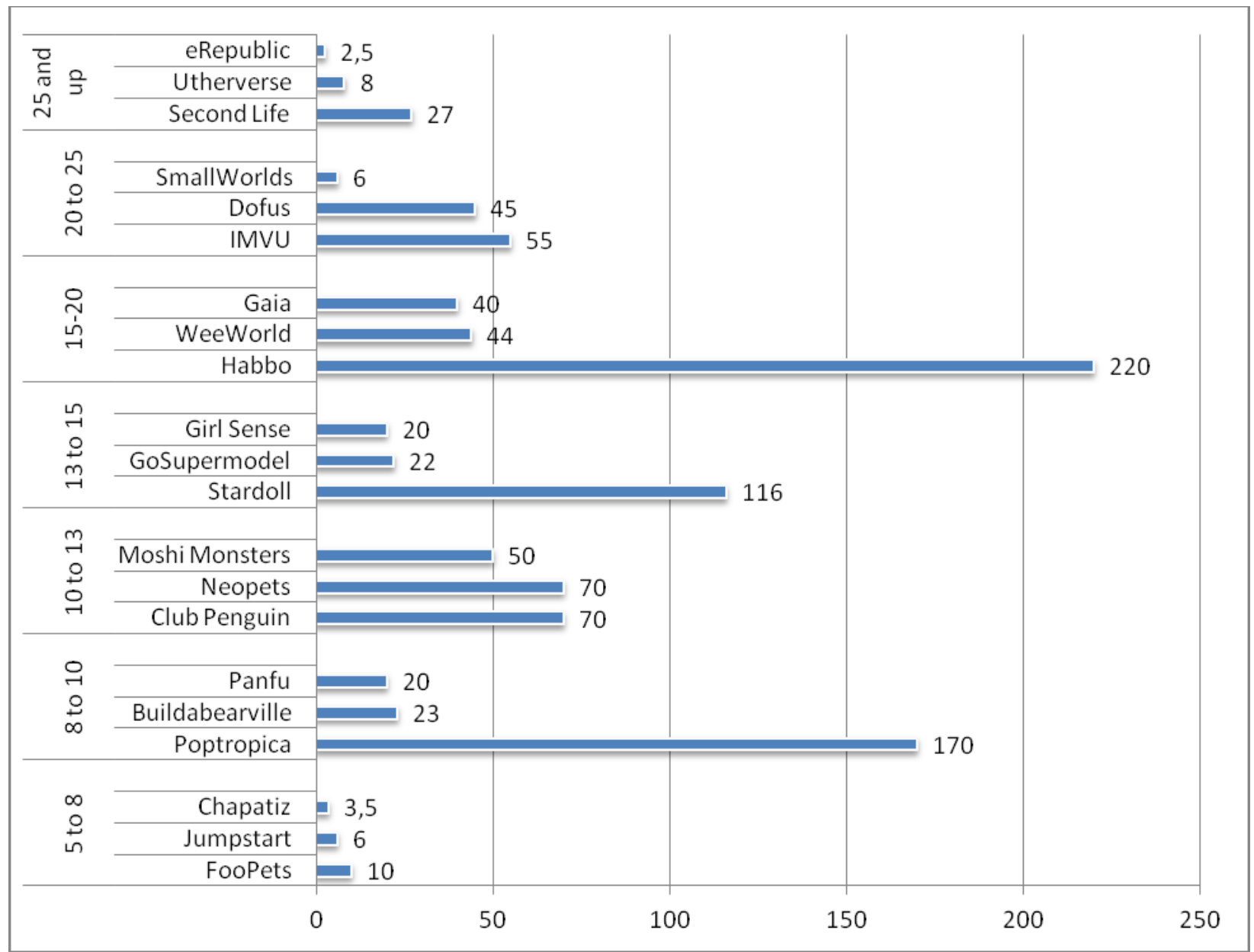

Figure 3. Some of the most popular Virtual Worlds, by age level (millions of users)

Even the least popular of these VWs (eRepublic) has over 2.5 million current users, with the most popular (Habbo) surpassing the 220 million player mark. As might be expected, the worlds aimed at younger users typically have a more basic (and cartoon-like) interface. Panfu, for example, is populated primarily by Pandas, while the default avatar in Club Penguin is-as might be expected - a tuxedo-clad flightless bird.

The majority of users of VWs are male, but it is certainly worth noting that this trend is changing. The three most popular VWs in the 13-15 age range are now all aimed at girls (Girl Sense, GoSupermodel, and Stardoll), and over 60\% of the users of Habbo are female (Kiss, 2010). This trend is in keeping with general Internet usage, where the vast majority of early users of the Internet were male while the current usage number in the U.S. (80\% of men and $76 \%$ of women online) is nearly even (Pew Internet, 2011). 
Although their popularity is one motivation for using VWs with our students, there is both theoretical background and research that supports their use (for a detailed examination of how learning theory-including work by Dewey, Vygotsky, Kolb, Levin, Long, and Ellisconnects to the use of VWs see Sadler (2011)). Almost all of the research accomplished in this area has been done since 2000-not surprising given the relative youth of these environments. Two edited volumes Higher Education in Virtual Worlds: Teaching and Learning in Second Life (Molka-Danielsen \& Deutschmann, 2009) and Learning and Teaching in the Virtual World of Second Life (Wankel \& Kingsley, 2009) and my own book Virtual Worlds for Language Learning: From Theory to Practice (2011) all contain research on using VWs for learning, and include discussion of cases where language learning was enhanced with these environments.

A number of studies have focused on collaborative nature of these environments (e.g., Churchill \& Snowdon, 1998; Brown \& Bell, 2004; Dickey, 2005; Price \& Rogers, 2004; Shaffer, Squire, Halverson, \& Gee, 2004; Gronstedt, 2007; Skiba, 2007; Ball \& Pearce, 2009). Both Brown and Bell (2004) and Dickey (2005) found that the object-oriented nature of these VWs helped to enhance their collaborative nature. This finding is echoed by Gronstedt, who sees Second Life as a "social networking tool" which by its very nature encourages collaboration (p. 46). Studies by both Bystrom \& Barfield (1999) and Steinkuehler (2004) found that students were able to complete tasks significantly better when working with a partner in comparison to working alone.

In addition to enhancing collaboration, other research has examined the role of VWs in reducing the anxiety level of language learners. Love, Ross, \& Wilhelm (2009) found that the use of VWs helped their students to "loosen up a bit..." (p. 68). One explanation for this is proposed by Brown and Bell, who found that the environment in the VW There "[allowed] communities of players to form who exchange new activities and forms of play with each other" (2004: 357). Because participants in VWs are being portrayed by their avatars, it means that they are not just “active, but also actors” (Dillenbourg, Schneider, \& Syntenta, 2002: 6). However, unlike the high anxiety that a student might face being on a RL stage, in the VW they may feel more secure behind the mask of their avatar. Because a student can be whoever (or whatever) they wish to be in a VW, Shaffer, et al., (2004), found that it gave their students the ability "to experiment with new and powerful identities" (p. 6) beyond what could be accomplished in a 
real world classroom. Perhaps the best overview of the advantages of using VWs as part of the educational process is offered by Jarmon, Traphaga, Mayrath, and Trivendi (2009), who maintain that VWs give:

(a) the capacity to host virtual social interactions and collaborations, (b) the capacity to allow users to test hypothesis by applying them to an actual project and doing something active (Kalyuga, 2007), without the risk and cost of the real world, (c) the possibilities for relevance of their virtual actions to the real world, (d) the capacity to allow for various types of activities to be practiced and demonstrated virtually, (e) the stimulation of imagination, exploration, and creativity, and (f) an increased sense of personal presence and tangible experience in the virtual world. (p. 179)

\section{What Virtual Worlds are Available?}

As discussed in the previous section, there are currently hundreds of VWs that may be of interest for educators, so this article will highlight a few that cover a range of potential environments and age ranges. As shown in Figure 4, many of these VWs may be used for free, with the exception of the one MMORPG listed, World of Warcraft (WoW). While this article will not discuss the use of WoW for language learning in detail, Thorne's (2008) examination of the intercultural communication that took place between a Ukrainian player of WoW with another player based in North America shows how even environments that many would consider very game-like still have strong potential for language learners.

\begin{tabular}{|l|l|l|l|l|l|}
\hline & Cost / month & Audience & Theme & Members & Installation \\
\hline Second Life & Free/ $\$ 9.95$ & $13+$ & Social & $27+$ million & Download \\
\hline$\underline{\text { Active Worlds }}$ & Free/ $\$ 6.95$ & unstated & Social & $2+$ & Browser add-on \\
\hline$\underline{\text { Habbo }}$ & Free/ $\$ 4.99$ & $13+$ & Hotel & $220+$ & Browser-based \\
\hline Club Penguin & Free/ $\$ 5.95$ & $6-14$ & Penguins! & $70+$ & Browser-based \\
\hline $\begin{array}{l}\text { World of } \\
\text { Warcraft }\end{array}$ & $\begin{array}{l}\text { \$14.99 }+ \\
\text { software }\end{array}$ & $\begin{array}{l}\text { Unstated, } \\
\text { but teen }+\end{array}$ & $\begin{array}{l}\text { Role play, } \\
\text { battle }\end{array}$ & $11+$ & Download \\
\hline $\begin{array}{l}\text { Custom-built } \\
\text { worlds }\end{array}$ & $\begin{array}{l}\text { Various, but } \\
\text { likely } \$\end{array}$ & Various & Various & Various & Various \\
\hline
\end{tabular}

Figure 4. Overview of Some Popular Platforms

\section{Second Life (SL)}

Second Life (shown in Figure 1) is the most popular VW amongst users in the 25 and above age bracket (see Figure 3). Prior to late in December of 2010 SL also had a totally separate grid—the 
Teen Grid - for users aged between 13 and 17, but that grid has now been combined with the main grid, with younger users restricted to limited areas. As with most VWs, SL does not have a set purpose- other than social. Instead, the users of SL who own their own sims (the name for an individual region in SL, equivalent to 65,536 sqm of land) can make their land into whatever they wish. Some sims looks like tropical islands, while others may be housing estates, shopping malls, recreations of RL cities like Paris or Ancient Rome, ballroom dancing clubs, battle sims, or whatever the owner can imagine. SL also has its own economy, based on the Linden. Many users of SL have their own virtual business in-world, where they sell products they have made. Lindens may also be traded in for one’s local currency in RL, and some users of this VW make their RL incomes solely by doing virtual business.

Most users of SL are not paid members, though premium membership (\$9.95 per month) does provide benefits like a free house and 300 Lindens for the user each week. Avatars communicate with each other in SL either via text or voice chat (see Sadler, 2011 for more on this). Unlike some of the VWs aimed at younger learners discussed below, there are no communications restrictions in SL. For educators who have their own space in SL, it is possible to link to that location via a system of SLURLs (Second Life URLs). This creates a landmark (similar to an Internet bookmark) for that location, which can then given to other avatars or placed on a course website. When the SLURL is clicked, it brings up a new page with a SL map. Clicking the teleport button on that map will link to the SL program (this assumes you have a SL account and are logged into the program) and allow people to teleport to that location. This SLURL (http://slurl.com/secondlife/EduNation\%20III/9/29/22/), for example, takes users to the EUROCALL/CALICO Headquarters on the EduNation Islands.

SL has a strong community of educators numbering in the thousands, including teachers working on a wide variety of languages. Users of SL are quite diverse in terms of their language backgrounds (SL avatars in 2009 represented 250 countries, territories, and regions). Although users from the U.S. make up the largest group of SL avatars, data provided by SL shows that in the third quarter of 2009 alone there were 13 countries whose users logged a total of at least one million hours in just those 3 months, and even countries with relatively fewer users hours represented (e.g. Greece, 610,000; Norway, 290,000; China, 290,000) still logged an amazing amount of time in-world. 
In a recent survey given to 237 SL users (see Sadler, 2011 for the full report), I found that there was a great deal of second language practice occurring in-world, with over $50 \%$ of participants reporting that they used another language in SL either usually or sometimes, and almost $80 \%$ claiming they used another language at least some of the time. When asked how they were improving their second language skills in SL (see Figure 5), I found a variety of strategies utilized. As shown in the table, the least frequent options related to more formal types of RL education-in other words the players did not seem to want to come to SL to attend the types of classes they were used to in RL.

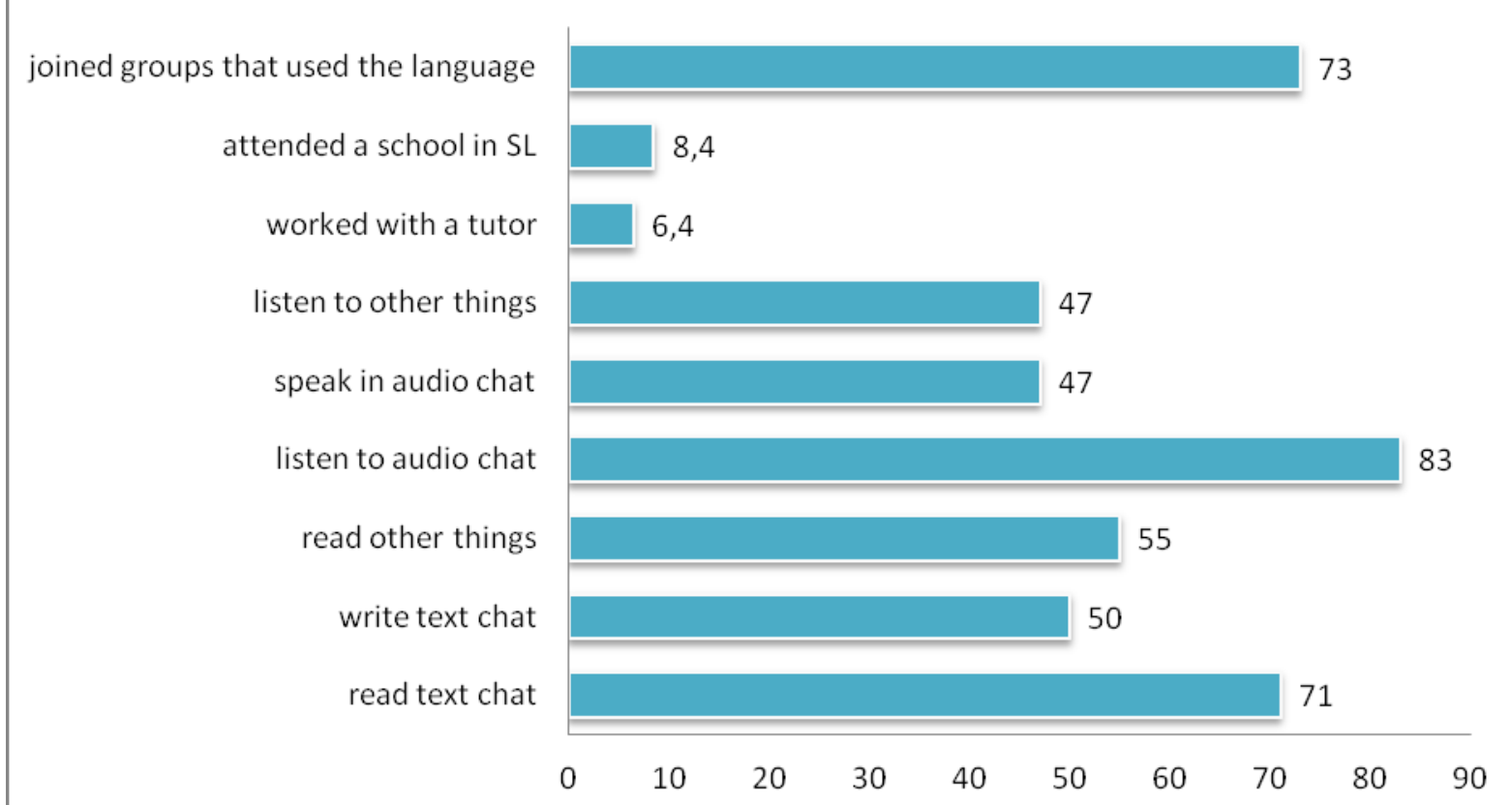

Figure 5. Language learning strategies utilized (by percentage of use)

While this paper does not have space for a detailed examination of language learning specifically within SL, several things are apparent:

1. Users are spending many hours in this world.

2. These users are diverse in terms of their nationalities and language backgrounds.

3. Many of them are practicing additional languages while in-world

This makes SL an attractive location for language practice for our students-no matter what language they are currently studying. At the same time, it is important to remember that SL is not intended for users under the age of 13 , and also that there are a number of sims in SL that are most definitely aimed at adults. While visitors to sims which are themed Adult must now be age 
verified, it is possible to stumble upon adult activities and/or views in other sims. SL does have policies related to harassment of minors, hate speech, etc., but it is one of the more open VW systems in terms of user restrictions (http://secondlife.com/corporate/tos.php?lang=en-US\#tos8). When working with younger students (13-18), islands dedicated to education and/or restricted to only registered users are the safer way to go.

\section{Active Worlds (AW)}

Active Worlds (see Figure 6) is a relative pioneer in the VW market, with an official launch in 1995. There are currently more than 1,000 worlds, with a virtual land mass larger than the state of California.

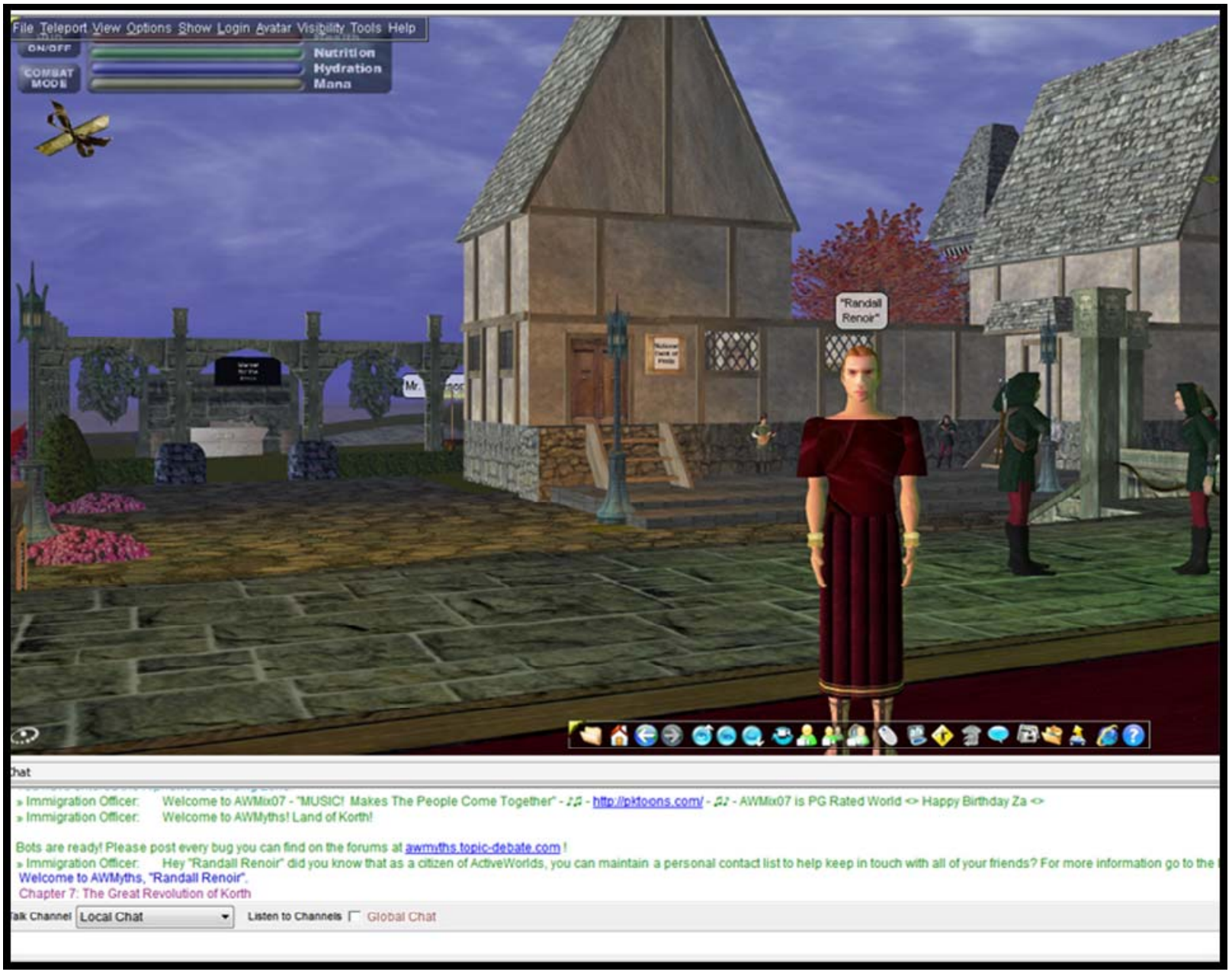

Figure 6. Active Worlds Myths 
As with SL, players may use AW at no cost (as tourists) though there are some important restrictions on them in comparison to SL. While citizens (\$6.95 per month) in AW may change their appearance and create permanent builds, this is not the case with tourists. In addition, tourists in AW have access to text chat, but do not have the ability to communicate with others via voice chat (though they can hear what others say). Active Worlds also has a strong focus on education, and created the Active Worlds Educational Universe (AWEU) where teachers can make use of AW at a discounted price. This universe currently has more than 80 worlds devoted to education.

Unlike SL, Active World's policy statement specifically prohibits both nudity and the display of sexually related materials:

- Displaying material containing nudity, pornography, or sexual material of a lewd, lecherous or obscene nature and intent or that violate local, state and national laws.

- $\quad$ Providing material that is grossly offensive to the online community, including blatant expressions of bigotry, prejudice, racism, hatred or excessive profanity. (http://www.activeworlds.com/community/terms.asp)

These policies, in conjunction with no specific age restrictions for users of AW and the strong educatoinal component make AW a good choice for educators. Unfortunately, AW has lost a great deal of popularity over the last decade, so it may sometime feel a bit on the empty side and seems to look less advanced than some of the other current VW choices. This makes it much more difficulty to find other users to talk to, especially if your students are searching for speakers of specific languages. However, for teachers looking for a virtual space to meet with a group of students (e.g. for a class exchange), AW may be an excellent choice.

\section{Habbo}

Habbo was created in 2000 in Finland (originally called Habbo Hotel). As might be guessed from the original name, this is a VW that takes place entirely within a hotel and its surroundings. Once again, anyone can get an avatar from this VW at no cost, with free users given a room in the hotel that may be customized to some extent. Players who pay for the Supersaver Subscription (\$4.99 per month) get 35 Habbo credits plus a monthly gift. Players can use those credits (or buy credits separately) to pay for VIP membership (25 credits per month, or about \$4 
U.S.) or to buy things ranging from pets to furniture to games. VIP membership gives additional customizing options for their rooms and also extra clothing and appearance options, etc. While it is sometime hard to think of money in terms of credits, a basic chair for a room in Habbo may be purchased for 3 credits, or about 50 cents. Habbo does not allow players under 13 years old.

Each Habbo hotel-more on the varieties later-consists of a number of public spaces in addition to the individual hotel rooms (which can be made either public or private by their owners). As seen in Figure 7, the hotel itself includes a variety of other spaces, such as waiting lounges, gardens, restaurants, social areas, a marketplace where users can buy items for their rooms or avatar, or even rooms associated with the hotel such as the Habbo Airport seen in the figure. Some of these spaces, such as the airport, are used by groups (which can be created by VIP members) for role play.

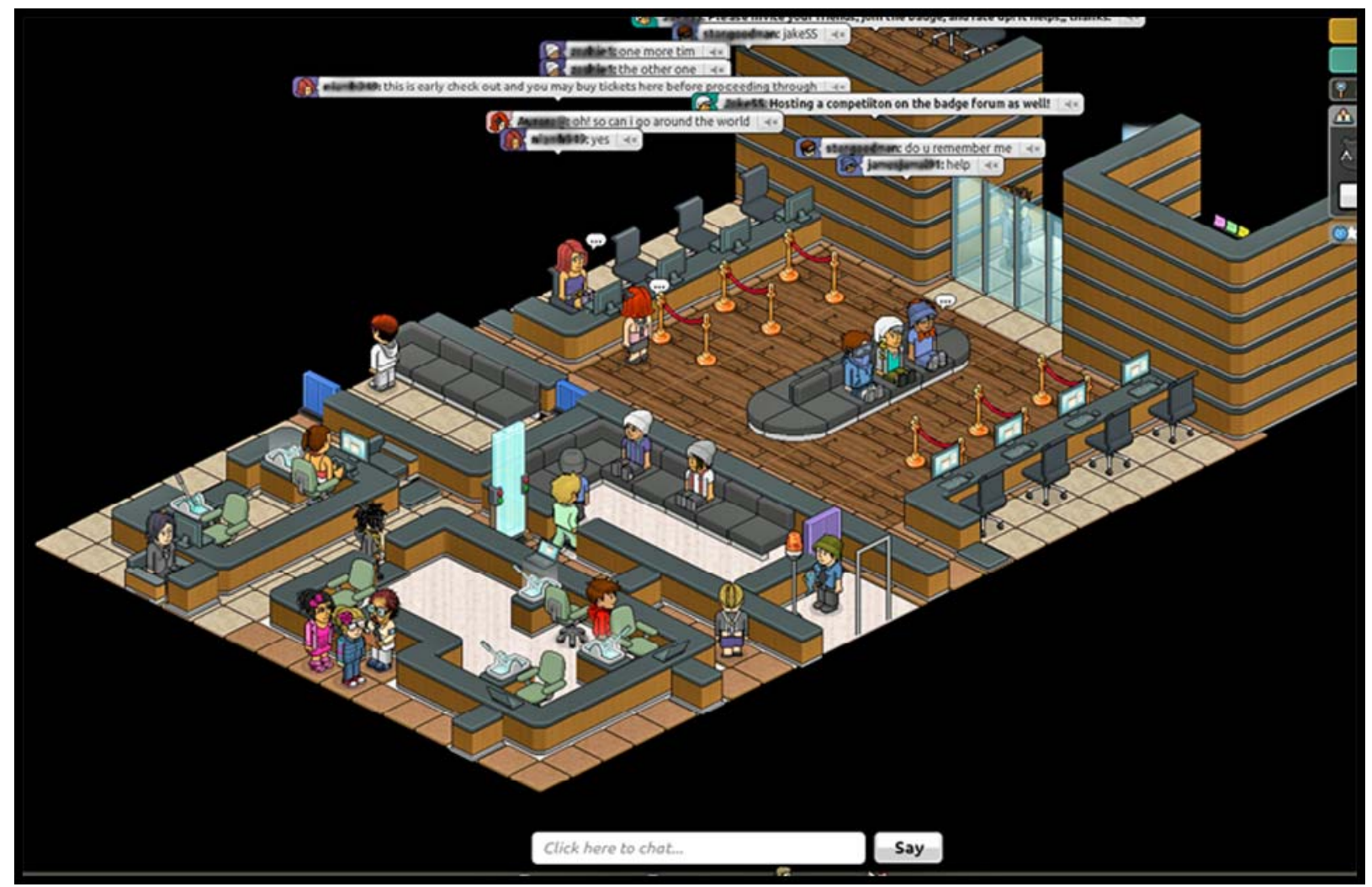

Figure 7. Habbo Airport Lounge

Communication in Habbo is more basic than in either SL or AW since Habbo does not include the possibility of voice communication. As seen in the figure, communication is text-based, and shows up as chat bubbles. While this is a disadvantage in that it allows for no vocal 
communication, many lower-level learners may find the text chat to be easier since they can take time to both read what others are saying and also put together their own messages at a slower rate.

One strong advantage of Habbo is that Facebook users may connect to Habbo via their Facebook accounts. Habbo users are also given their own customizable homepage (SL users also have profile pages), and have the ability to add links to their hotel room (or other public areas) via another webpage (useful to link to a room via your course website). Movement in Habbo is accomplished by clicking on the area where the user wishes her avatar to go, and the avatar then makes her way to the selected location without further assistance (a simpler technique than either SL or AW, but not quite as flexible). Another potential draw for language educators is that Habbo is divided into a number of individual communities, largely based on language (see Figure 8). This means that users from Finland log in automatically to Habbo Finland, while U.S. users go to their own Habbo. There are currently 32 Habbo communities around the world. While getting from one version of Habbo to another is not immediate transparent, it is possible to $\log$ into another Habbo if you know the correct URL (http://www.sulake.com/habbo). For students looking to practice another language, this gives an immediate and easy method to find a large pool of native speakers of that language.

\begin{tabular}{lllll}
\hline Argentina & Australia & Austria & Belgium & Brazil \\
\hline Canada & Chile & Columbia & Denmark & Ecuador \\
Finland & France & Germany & Ireland & Italy \\
Malaysia & Mexico & Netherlands & New Zealand & Norway \\
Peru & Portugal & Singapore & Spain & Sweden \\
Switzerland & UK & USA & Venezuela & Morocco \\
Philippines & Uruguay & & & \\
\hline
\end{tabular}

Figure 8. Habbo Local Communities

Another advantage of using Habbo for teens is that the company has a strong community safety policy:

Providing a safe social environment for the users is a top priority in Habbo. In order to keep the community as safe as possible, Habbo uses active moderation, user education and automatic language filtering. Habbo is constantly patrolled by adult moderators who follow the discussions, kick out and ban wrongdoers and help the users with their questions. In Habbo Home users are also provided with an additional reporting tool, which enables them to report inappropriate content to the staff members. (http://www.sulake.com/habbo). 
Habbo also uses a language-specific system of active moderation that filters out inappropriate language. This means that swear words don't appear in the text chat and are instead replaced by the word bobba (e.g. in the text chat "Bobba you!" might appear instead of something much ruder). Teens, of course, do their best to find ways around this system.

While Habbo does have some significant advantages, especially for younger teen users, it does not have the same flexibility of more "complete" VWs like AW or SL. In those worlds users can purchase islands or sets of islands and create entire worlds that can be customized to a level of detail that is not possible in Habbo. In addition, avatars in SL (and to a lesser extent AW) can be individualized much more extensively than in Habbo-a feature that helps to connect users more strongly to their avatars. On the other hand, the level of detail allowed in those worlds also means that a nude avatar in a world like SL may be graphically nude in a way that would never be possible in Habbo. Choosing the correct world for teen users depends on the level of teacher involvement and whether a school can afford to have their own space in SL where students are much more restricted.

\section{Club Penguin}

Unlike the VWs discussed up to this point, Club Penguin (online in 2005 and bought by Disney in 2007) is aimed at children between 6 - 14, though most children over the age of 10 might find it a bit too juvenile for their tastes. As seen in Figure 9, the avatars in Club Penguin mirror the name of the VW. Club Penguin has a variety of environments for users to explore, ranging from beaches, to plazas, to mines and ski hills. Club Penguin is similar to Habbo in that it is a more structured environment without some of the flexibility of SL and AW. However, in the case on younger users this is not necessarily a bad thing. Once again, players may use this VW for free, but paid members have access to more games and levels on the site and can also customize their igloo to a much greater extent than free users.

Club Penguin — like Habbo—also has the potential to be used in other languages. At the current time, when logging in players can click a language select button to choose from English, Spanish, Portuguese, French, and German. Once the language is chosen, the system changes to instructions in that language and the majority of the communication by players seems to take 
place in that language. Club Penguin is also very focused on providing a safe environment for its users, more so than any of the VWs discussed thus far.

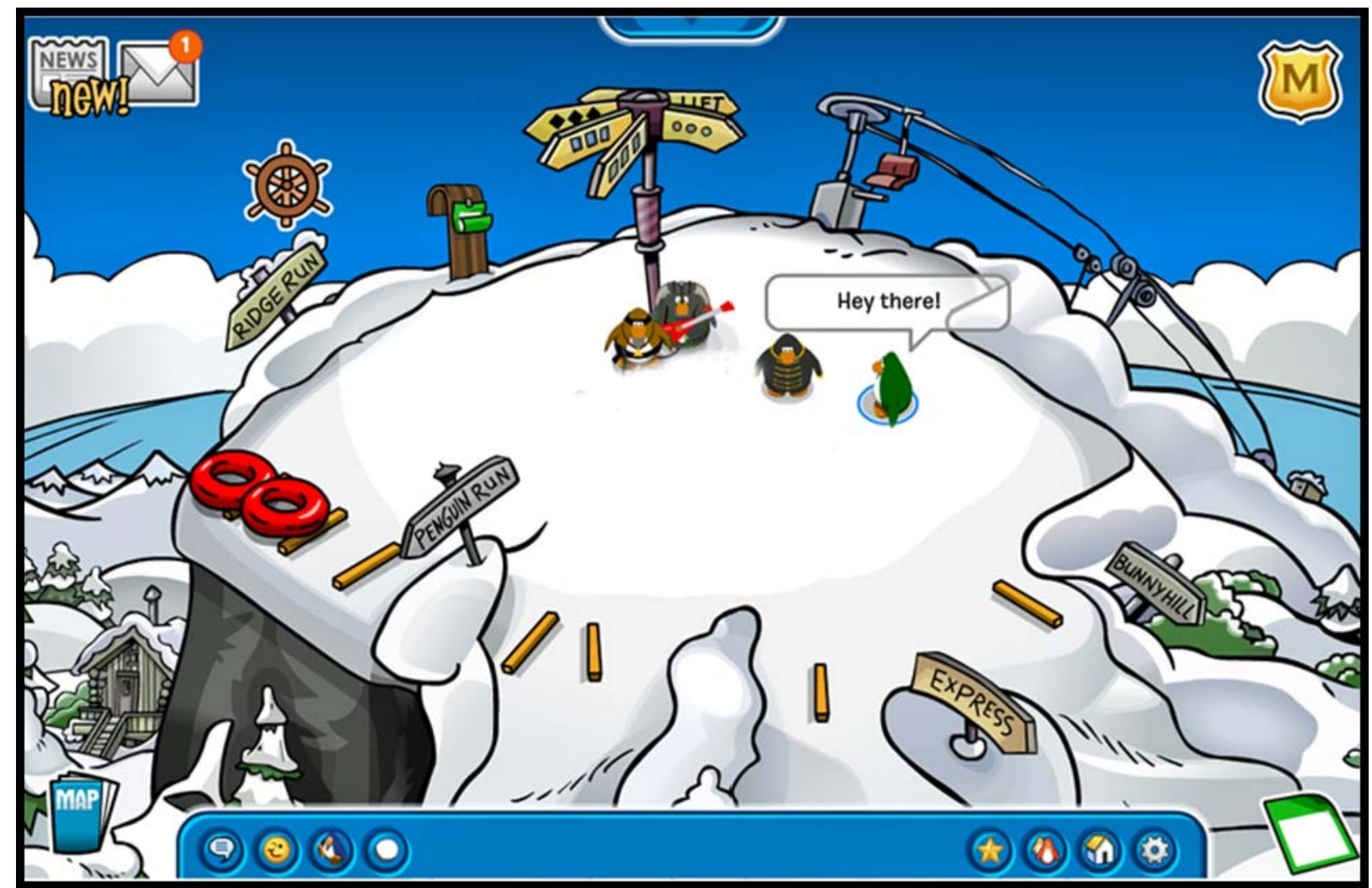

Figure 9. Club Penguin-Ski Hill

The site includes no outside advertising and provides live moderation by Club Penguin employees. Any player who sees or experience inappropriate behavior can click the Moderator button (seen in the top right of Figures 9 and 10) and directly contact an adult for help. This VW also allows players (or their parents or teachers) to choose from two levels of chat:

Ultimate Safe Chat limits what users can say to a predefined menu of greetings, questions and statements, as well as emotes, actions and greeting cards. When it comes to chatting, these users can only see other Ultimate Safe Chat Messages.

Standard Safe Chat allows players to type their own messages to other users. Every message is filtered to allow only pre-approved words and phrases, and block attempts to communicate a phone number or other personally identifiable information. (http://www.clubpenguin.com/parents/player_safety.htm)

As seen in Figure 10 (this time playing in the Spanish version of Club Penguin), an Ultimate Safe Chat area allows the players to communicate only via a game-based interface where they 
choose from set menus. In this version of the communication, the user has access to a number of initial topic headings that can be accessed by first clicking on the chat bubble at the bottom of the screen (to the right of the Mapa (Map) icon). As seen in the figure, these include topics like Hola (Hello), Adiós (Goodbye), Amigo (Friend), Preguntas (Questions), etc. In this case, selecting Preguntas brought up a secondary menu as seen in the figure. When I selected ¿Cuál es? (Which is?) another menu came up with possible questions such as the one highighted on the screen: ¿Cuál es tu deporte favorito? (Which is your favorite sport?). Once selected, that question would then appear on the screen in a chat bubble like the one shown earlier in figure 9. Another player could then answer the question via a similar process, starting with clicking on the Respuestas (answers) button. Players in the Standard Safe Chats area do not have to choose from pre-defined menus so they have more flexibility in their communication. However, as mentioned above, their communication is still restricted in some ways to keep communication safe.

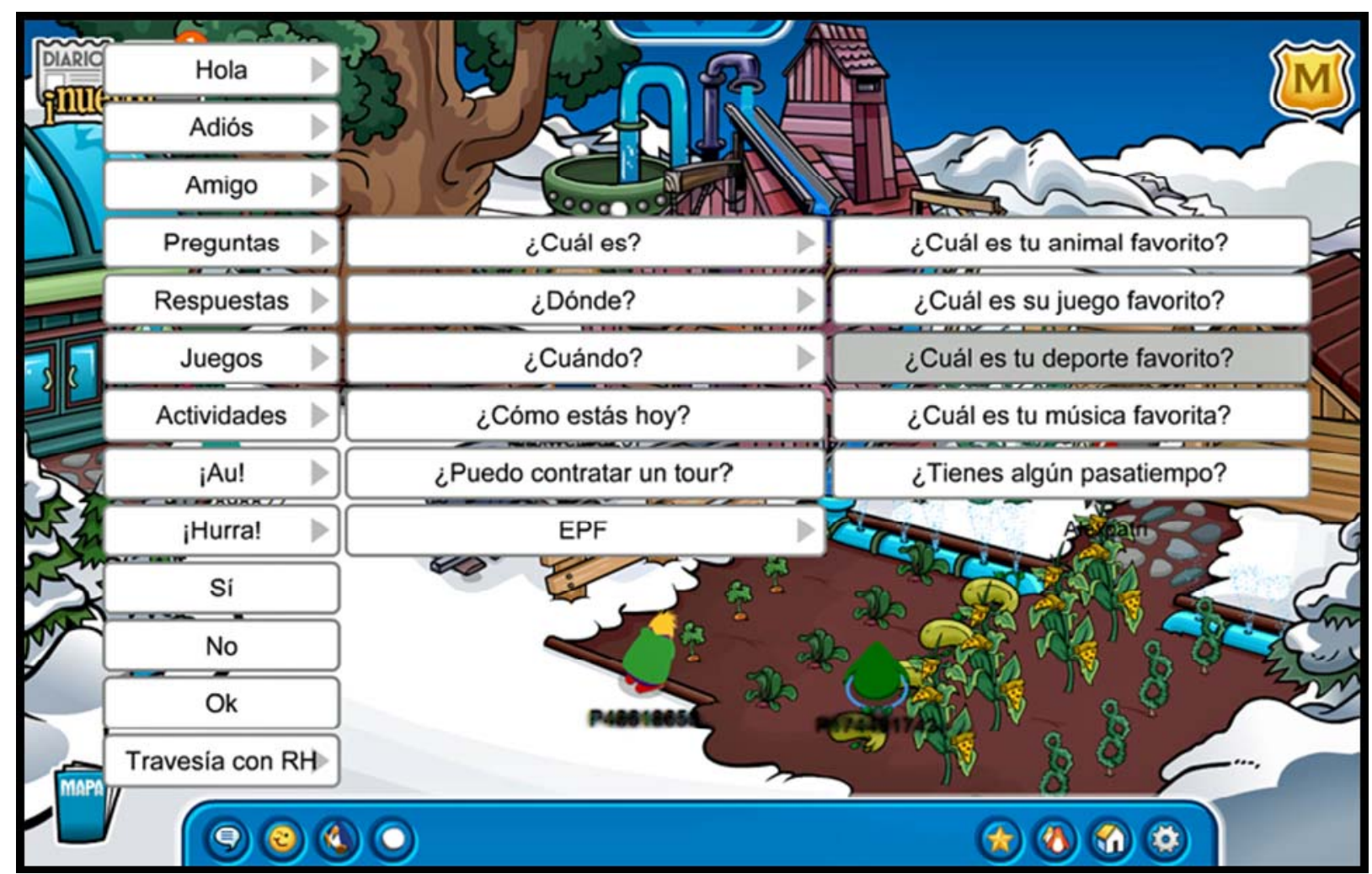

Figure 10. Ultimate Safe Chat area 
Club Penguin does not allow for voice chat, but players do have access to a number of emoticons and also actions (e.g. waving) via the menu interface. This VW also has a weekly newspaper, The Club Penguin Times, with news, user-submitted questions, an advice column, and more.

For teachers with younger students who are studying one of the languages provided by Club Penguin, this VW is a safe place for your students to practice that language. While the Ultimate Safe Chat areas are certainly somewhat restrictive, they are also excellent places for beginning language learners to go where they will be exposed to only a limited amount of input choices. This will help them to not be overwhelmed by too many unknown words. At the same time, the menu interface will also allow them to communicate with other speakers of the language under study at a much greater level of success than they would be able to accomplish at an early stage of learning in oral communication. For more advanced learners, the Standard Safe Chat areas open up the communicative potential so that the learners can expand both their input and output possibilities.

\section{Custom-built worlds/SIEs}

These types of VWs are sometimes referred to as Synthetic Immersive Environments (SIEs), particularly when they are "designed to target educational objectives through the creation of a meaningful collaborative space in which the participants are directly engaged in activity related to specific domains of knowledge” (Thorne, Black, \& Sykes, 2009, p. 812). From the perspective of users, custom-build VWs may appear to be indistinguishable from some of those that are commercially available or they be true custom environments ${ }^{2}$. In some cases, this may be due to the use of open-source systems that are nearly identical to commercial products. One of the most popular of these systems is Open Simulator (Open Sim: http://opensimulator.org/wiki/Main _Page). According to its creators, Open Sim:

...can be used to simulate virtual environments similar to Second Life ${ }^{\mathrm{TM}}$, given that it supports the core of SL's messaging protocol. As such, these virtual worlds can be accessed with the regular SL viewers. However, OpenSimulator is neither a clone of Second Life's server nor does it aim at becoming such a clone. On the contrary, OpenSimulator lacks support for many of the game-specific features of Second Life (on purpose), while pursuing innovative directions towards becoming the bare bones, but extensible, server of the 3D Web. 
For educators, Open Sim can offer an enviromnent where students can have a VW meeting place where they might engage in collaboration with students from another school without the potential problems and/or distractions of a full VW such as SL.

Custom-build environment of this sort can be made absolutely secure so that only avatars pre-approved by the owner of the sim are allowed into the sim (this can also be accomplished in SL, but users may easily leave SL islands-this is not necessarily the case with Open Sim). While some technically saavy educators might choose to install the Open Sim system onto their own servers (if they happen to have one!), there are also a number of businesses that will rent out sims using the Open Sim platform for costs that are much lower than buying a sim from SL. There are many providers that use the Open Sim platform, and one that I have made use of is Dreamland Metaverse, which has sims costing as little as \$30 U.S. per month. A similar island in SL (though SL sims have more features) would cost almost \$300.00 per month. Open Sim islands allow for the same types of communication as SL—both text and oral chat-and avatars in this system can also be highly customized.

While the safety and cost of Open Sim can make it an attractive option, there is also much less support available for users in that environment (though the community of Open Sim users are very supportive of each other!). Users of SL, for example, can easily find many thousands of free items that they can use for housing and education-enough to design and furnish an entire island. In addition, SL has an online shopping system (Second Life Marketplace) that contains hundreds of thousands of items that may be bought or sometimes found at zero cost. As mentioned earlier, Second Life provides users with access to thousands of islands that are all connected via the SL teleport system. Although Open Sim looks very similar to SL, Open Sim users cannot directly access SL islands. While this can be an advantage for teachers who want a safe and secure environment (and who don't want their students suddently teleporting away to some other island), this also means that users of Open Sim don't have access to the great variety of islands in SL (as mentioned earlier you can take your students to visit SL Paris). So, for more technically advanced educators, or those who have good tech support available, Open Sim can help in the creation of a secure environment for your students. However, for those who are technically challenged, this may not be the right choice. 


\section{Conclusion}

This article provided an overview of Virtual Worlds and their potential for use by language educators. As mentioned earlier in the article, there are many hundreds of VWs to choose from for teachers, so the five options examined briefly here (Second Life, Active Worlds, Habbo, Club Penguin, and Open Sim) only scratch the surface of those possibilities. However, as discussed, not all of these VWs suited for all students. Some, like Club Penguin, are aimed at younger learners and may offer opportunities for beginning language students to engage in communication with native speakers of the language in a way that will give them low stress opportunities for success. Others, like Second Life, are more appropriate for older learners who are mature enough to both appreciate the opportunities for authentic communication that such a VW provides but who also will not be distracted by some of the less savory locations available. As a teacher, your role must be to explore some of these environments on your own and to choose the world that best suits the needs of your students.

\section{Bibliography}

Ball, S. \& Pearce, R. (2009). Inclusion benefits and barriers of "once removed" participation. In C. Wankel \& J. Kingsley (Eds.), Higher education in virtual worlds: Teaching and learning in Second Life (pp. 47-63). Bingley: Emerald.

Brown, B. \& Bell, M. (2004). CSCW at play: 'There' as a collaborative virtual environment. Paper presented at the 2004 ACM Conference on Computer Supported Cooperative Work, Chicago, Illinois.

Bystrom, K.-E. \& Barfield, W. (1999). Collaborative task performance for learning using a virtual world. Presence, 8(4), 435-448.

Churchill, E. F. \& Snowdon, D. (1998). Collaborative virtual environments: An introductory review of issues and systems. Virtual Reality, 3, 3-15.

Dickey, M. D. (2005). Three-dimensional virtual worlds and distance learning: Two case studies of Active Worlds as a medium for distance education. British Journal of Educational Technology, 36(3), 439-451.

Dillenbourg, P., Schneider, D. \& Synteta, P. (2002). Virtual learning environments. Paper presented at the 3rd Hellenic Conference "information \& communication technologies in education".

Gibson, W. (1984). Neuromancer. New York: Ace Books.

Gronstedt, A. (2007). Second Life produces real training results: The 3-D web world is slowly becoming part of the training industry. Training and Development, 44-49. 
Jarmon, L., Traphagan, T., Mayrath, M. \& Trivedi, A. (2009). Virtual world teaching, experiential learning and assessment: An interdisciplinary communication course in Second Life. Computers \& Education, 53, 169-182.

Kiss, J. (2010, July 5). Ten years of virtual worlds: Habbo hits a decade. The Guardian. Retrieved Feb. 12, 2012 from < http://www.guardian.co.uk/media/pda/2010/jul/05/habbovirtual-worlds $>$.

KZERO (2010). KZERO Worldwide. Retrieved February 2, 2010 from $<$ http://www.kzero.co.uk/\#>.

Love, E., Ross, S. C. \& Wilhelm, W. (2009). Opportunities and challenges for business education in Second Life. In C. Wankel \& J. Kingsley (Eds.), Higher education in virtual worlds: Teaching and learning in Second Life (pp. 65-82). Bingley: Emerald.

Molka-Danielsen, J. \& Deutschmann, M. (Eds.). (2009). Learning and teaching in the virtual world of Second Life. Trondheim: Tapir Academic Press.

mmohut (2010). mmohut: Free online MMORPG and MMO games. Retrieved January 16, 2010 from <http:// mmohut.com>.

mmorpg.com (2010). mmorpg. Retrieved January 11, 2010 from <http://.mmorpg.com/>.

Pew Internet (2011). Demographics of Internet Users. Retrieved February 16, 2012, from < http://www.pewinternet.org/Trend-Data/Whos-Online.aspx>.

Price, S. \& Rogers, Y. (2004). Let's get physical: The learning benefits of interacting in digitally augmented physical spaces. Computers and Education, 43, 137-151.

Shaffer, D. W., Squire, K. R., Halverson, R. \& Gee, J. P. (2004). Video games and the future of learning. Madison: University of Wisconsin-Madison and Academic Advanced Distributed Learning Co-Laboratory.

Sadler, R. (2011). Virtual Worlds for Language Learning: From Theory to Practice. Bern: Peter Lang.

Skiba, D. J. (2007). Nursing education 2.0: Second Life. Nursing Education Perspectives, 28(3), 156-157.

Steinkuehler, C. A. (2004). Learning in massively multiplayer online games. Paper presented at the International Conference on Learning Sciences, Santa Monica, California.

Stephenson, N. (1992). Snow Crash. New York: Bantam Spectra.

Sykes, J. M. (2008). A dynamic approach to social interaction: Synthetic immersive environments \& Spanish pragmatics (Unpublished doctoral dissertation). University of Minnesota.

Thorne, S. L. (2008). Transcultural communication in open internet environments and massively multiplayer online games In S. Sieloff Magnan (Ed.), Mediating discourse online (pp. 305327). Amsterdam: John Benjamins.

Vinge, V. (2001). True Names. In: Frenkel, J. (ed.), True names and the opening of the cyberspace frontier (pp. 239-330). New York: TOR.

Wachowski, A. \& Wachowski, L. (Writer) (1999). The Matrix [film].

Wankel, C. \& Kingsley, J. (Eds.) (2009). Higher education in virtual worlds: Teaching and learning in Second Life. Bingley: Emerald Group Publishing Limited.

\footnotetext{
${ }^{1}$ Names of other avatars have been either blurred or entirely eliminated in all images to protect their identities.
} 
${ }^{2}$ For an example of custom-built SIE see Sykes' (2008) work on Croquelandia —a SIE designed to simulate a Spanish-speaking marketplace.

\begin{abstract}
Author's Reference:
Dr. Randall Sadler is an Associate Professor of Linguistics at the University of Illinois at Urbana-Champaign, where he teaches courses on Computer-Mediated Communication and Language Learning (CMCLL), Virtual Worlds and Language Learning (VWLL) and Teaching of Second Language Reading and Writing. His main research focus is on the role of technology in language learning, with a particular focus on how Virtual Worlds may be used to enhance that process. He has published in these areas in journals including the Journal of English for Academic Purposes, CALICO Journal, and Computers \& Education. His latest book, Virtual Worlds, Telecollaboration, and Language Learning: From Theory to Practice will be published by Peter Lang this year. He is also the co-owner of the EduNation Islands, which are located in the Virtual World Second Life ${ }^{\mathrm{TM}}$, where he may often be found in the guise of his avatar Randall Renoir.

Email: rsadler@illinois.edu
\end{abstract}

To cite this article:

Sadler, R. (2012). Virtual worlds: An overview and pedagogical examination. Bellaterra Journal of Teaching \& Learning Language \& Literature, 5(1), 1-22. 